\title{
Factors associated with length of stay in hospital among the elderly patients using count regression models
}

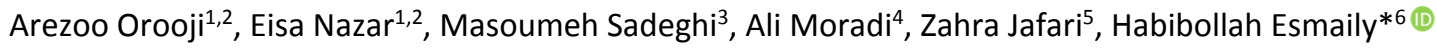 \\ Received: 30 Sep 2019 \\ Published: 11 Jan 2021
}

Abstract

Background: Aging is a major challenge not only for high-income countries but also for middle- and low-income countries. The length of stay (LOS) in hospitals is one of the major concerns of elderly patients, which should be taken into consideration. We aimed to investigate the factors affecting LOS of elderly patients admitted to a referral hospital of northeast of Iran.

Methods: A relatively large population of 7130 hospitalized elderly patients (over 65 years old) who referred to Ghaem hospital (Mashhad, Iran) from March 20, 2016 to March 19, 2017 were selected. The demographic and medical records data of patients were extracted from the hospital database. Univariate analyses as well as count regression models, including poisson regression and negative binomial regression, were conducted to assess the influential factors on the LOS and the number of admissions considered for potential confounders using SAS software. In this study $\alpha=0.05$ was considered as statistically significant.

Results: The mean age of participants was $76.57 \pm 7.29$ years, and $54.8 \%$ were male and $45.2 \%$ were female. The mean LOS was $8.11 \pm 13.97$ days and the mean number of admissions $1.5 \pm 1.73$ times. The negative binomial regression model had better fitness than Poisson's model. Findings indicated that emergency hospitalization (RR: 0.21), admission to the CCU (RR: 0.33), and male gender (RR: 0.92) were statistically reducing factors for LOS among elderly patients, respectively. Discharge status (deceased, RR: 1.50), patients with diagnosis of injuries and poisoning (RR: 1.34), and native residence (RR: 1.10) were factors that statistically increased the length of stay among hospitalized elderly patients.

Conclusion: LOS in hospitals is affected by multiple factors and the negative binomial regression model is a better statistical method for estimating the influencing factors.

Keywords: Elderly, Length of stay, Count regression models, Negative binomial regression

Conflicts of Interest: None declared

Funding: None

*This work has been published under CC BY-NC-SA 1.0 license.

Copyright $@$ Iran University of Medical Sciences

Cite this article as: Orooji A, Nazar E, Sadeghi M, Moradi A, Jafari Z, Esmaily H. Factors associated with length of stay in hospital among the elderly patients using count regression models. Med J Islam Repub Iran. 2021 (11 Jan);35:5. https://doi.org/10.47176/mjiri.35.5

\section{Introduction}

In recent years, life expectancy has been longer than ever before. Aging is a natural and unavoidable process. This phenomenon is not restricted to the high-income

\section{Corresponding author: Dr Habibollah Esmaily, esmaeilyh@mums.ac.ir}

1. Student Research Committee, Mashhad University of Medical Sciences, Mashhad, Iran

2. Department of Biostatistics, Faculty of Health, Mashhad University of Medical Sciences, Mashhad, Iran

3. Department of Epidemiology, Faculty of Health, Mashhad University of Medical Sciences, Mashhad, Iran

4. Orthopedic Research Center, Mashhad University of Medical Sciences, Mashhad, Iran

5. Clinical Research development Unit, Ghaem Hospital, Mashhad University of Medical Sciences, Mashhad, Iran

6. Social Determinants of Health Research Center, Mashhad University of Medical Sciences, Mashhad, Iran countries but is also a major challenge for middle-and low-income countries, meaning that aging is a global phenomenon. By $2050,80 \%$ of all older people will live in

\section{$\uparrow$ What is "already known" in this topic:}

Elderly population in Iran is considerably mounting. It is estimated the number of seniors over 60 years will be more than 26 million by 2025 .

\section{$\rightarrow$ What this article adds:}

Length of stay in hospitals among elderly patients is affected by protective factors, including emergency hospitalization, admission to the CCU, and gender (male), respectively. Factors that resulted in increased LOS were discharge status (Deceased), patients with diagnosis of injuries and poisoning, and native residence, respectively. Negative binomial regression model is a better statistical method for estimating the influencing factors on LOS. 
low- and middle-income countries based on World Health Organization reports (1).

Given that different age groups have different needs, it is necessary that the economic characteristics and health priorities of the countries change based on its age pyramid population. Increasing number of the elderly brings concerns with hospitalization and length of stay (LOS) $(2,3)$. LOS usually refers to the number of days that a patient spends in hospital and uses health care facilities during this period (4-6). Length of stay is the simplest and most useful indicator of hospital activity which is used to assess hospital care management, hospital planning, and quality of patient care; also, it can be considered as an important factor for hospital management to examine the efficiency and effectiveness of hospital services (7). Since health centers, including hospitals, faced with resource constraints, reducing the length of hospital stay is a desirable and effective strategy to reduce unnecessary hospitalization cost. As in most middle-income countries, the elderly population in Iran is considerably mounting (8). It is estimated the number of seniors over 60 years $(9,10)$ will be more than 26 million by 2025 (11).

Evaluating the LOS of the elderly and its associated factors to determine priorities, improve the services, and allocate appropriate resources is helpful in terms of the difference in the length of stay of the patients (12). Mashhad is the capital of the province in the northeast of Iran and many patients from adjacent provinces refer to this city to receive medical services. The aim of this study was to investigate the demographic and clinical factors affecting hospital LOS of admitted elderly patients to Ghaem hospital in Mashhad using count regression models.

\section{Methods}

This was an analytical cross sectional study. The eligible study population $(n=7130)$ consisted of all hospitalized elderly patients over 65 years who referred to Ghaem hospital (an educational hospital in Mashhad, northeast of Iran), with complete medical records data from March 20, 2016 to March 19, 2017. Outpatient elderly, patients under 65 years, patients with missing medical records data, and those who were hospitalized outside the study time range were excluded.

The demographic characteristics and medical records of patients (including gender, residence status, type of insurance, patient diagnosis type, inpatient ward, discharge status, and type of hospitalization) were extracted from the hospital information system (electronic medical records database).

To investigate the factors affecting LOS of the elderly, univariate analysis was used using an independent $t$ test, one-way ANOVA, Mann-Whitney U test, Pearson's correlation coefficient, and Kruskal-Wallis tests. Count regression models, including poisson regression and negative binomial regression, were used to explore the factors associated with LOS and the number of admissions. The count regression models are used when the response variable is countable, and as LOS and the number of admissions are countable variables, these models were used. The most common count regression models are poisson regression and negative binomial regression. Akaike information criterion (AIC) was used to compare the models and choose the best one. Data were analyzed using SAS Ver. 9.4 , and $\alpha=0.05$ was considered as statistically significant.

\section{Results}

A total of 7130 elderly patients had been referred to Ghaem hospital, of whom $3221(45.2 \%)$ were women and 3909 (54.8\%) were male. The mean age of the patients was $76.57 \pm 7.29$ years. The mean LOS was $8.11 \pm 13.97$ days and the mean number of admissions was $1.5 \pm 1.73$ times. Most hospitalizations were elective admissions, but the average LOS was higher in emergency admission, 9.94 vs 6.99 days. The average length of stay in inhabitants/ natives and in the spring was more than nonnative patients and other seasons. A considerable percentage of the elderly were discharged after recovery, $16.7 \%$ were discharged due to death, and only $1.7 \%$ were discharged for follow-up treatment. The highest LOS was for patients who were discharged due to death. A significant difference was found in the LOS of the elderly admitted to different hospital wards, and the highest and lowest average LOS was in ICU and CCU wards, respectively.

The results of univariate analysis showed a significant association between all study variables and length of stay (LOS) (Table 1), except for patients' type of insurance $(\mathrm{p}=0.95)$.

\begin{tabular}{|c|c|c|c|c|}
\hline \multirow[t]{2}{*}{ Variable } & \multicolumn{3}{|c|}{ LOS } & \multirow[t]{2}{*}{$\bar{p}$} \\
\hline & Number & Percentage & Mean \pm SD & \\
\hline \multicolumn{5}{|l|}{ Gender } \\
\hline Female & 3221 & 45.2 & $8.53 \pm 1313$ & \multirow[t]{2}{*}{$<0.010$} \\
\hline Male & 3909 & 54.8 & $7.80 \pm 10.91$ & \\
\hline \multicolumn{5}{|c|}{ Type of hospitalization } \\
\hline Elective & 3782 & 53 & $6.99 \pm 10.20$ & \multirow[t]{2}{*}{$<0.001$} \\
\hline Emergency & 3348 & 47 & $9.94 \pm 13.58$ & \\
\hline \multicolumn{5}{|c|}{ Season of hospital of visit } \\
\hline Spring & 1798 & 25.2 & $8.92 \pm 15.46$ & \multirow[t]{4}{*}{$<0.001$} \\
\hline Summer & 1830 & 25.7 & $8.48 \pm 12.28$ & \\
\hline Fall & 1828 & 25.6 & $7.98 \pm 1.29$ & \\
\hline Winter & 1674 & 23.5 & $7.08 \pm 8.44$ & \\
\hline \multicolumn{5}{|l|}{ Residence } \\
\hline Non-native & 2493 & 35 & $7.33 \pm 9.97$ & \multirow[t]{2}{*}{$<0.001$} \\
\hline Native & 4637 & 65 & $8.56 \pm 12.90$ & \\
\hline
\end{tabular}




\begin{tabular}{|c|c|c|c|c|}
\hline \multirow[t]{2}{*}{ Variable } & \multicolumn{3}{|c|}{ LOS } & \multirow[t]{2}{*}{$\mathrm{p}$} \\
\hline & Number & Percentage & Mean \pm SD & \\
\hline \multicolumn{5}{|l|}{ Discharge status } \\
\hline Recovery & 5107 & 71.6 & $7.9 \pm 63.73$ & $<0.001$ \\
\hline Personal satisfaction & 712 & 10 & $6.40 \pm 10.54$ & \\
\hline Deceased & 1191 & 16.7 & $11.23 \pm 19.12$ & \\
\hline Follow up treatment & 120 & 1.7 & $9.06 \pm 8.79$ & \\
\hline \multicolumn{5}{|l|}{ Ward/Department } \\
\hline Internal & 1910 & 26.8 & $12.24 \pm 13.61$ & $<0.001$ \\
\hline Surgery & 1751 & 24.6 & $6.36 \pm 7.53$ & \\
\hline ICU & 225 & 3.2 & $17.71 \pm 17.04$ & \\
\hline Heart/Cardio & 964 & 13.5 & $5.49 \pm 6.26$ & \\
\hline Open Heart Surgery (CABG) & 218 & 3.1 & $11.58 \pm 12.58$ & \\
\hline $\mathrm{CCU}$ & 319 & 4.5 & $4.50 \pm 4.77$ & \\
\hline Emergency & 1743 & 24.4 & $5.87 \pm 14.04$ & \\
\hline \multicolumn{5}{|l|}{ Type of Insurance } \\
\hline Health Service & 4405 & 61.8 & $8.09 \pm 11.56$ & 0.952 \\
\hline Social Security & 2131 & 29.9 & $8.19 \pm 12.89$ & \\
\hline Insured by Armed forces & 594 & 8.3 & $8.18 \pm 11.50$ & \\
\hline Diagnosis & & & & $<0.001$ \\
\hline Infectious and Parasitic Diseases & 247 & 3.5 & $9.50 \pm 11.44$ & \\
\hline Cancers & 850 & 11.9 & $8.10 \pm 9.36$ & \\
\hline Metabolic and Endocrine Diseases & 146 & 2 & $7.60 \pm 7.98$ & \\
\hline Diseases of the Nervous System & 184 & 2.6 & $10.03 \pm 13.92$ & \\
\hline Circulatory System Diseases & 2755 & 38.6 & $8.29 \pm 13.95$ & \\
\hline Respiratory System Diseases & 722 & 10.1 & $11.51 \pm 15.12$ & \\
\hline Gastrointestinal Diseases & 722 & 10.1 & $8.08 \pm 8.69$ & \\
\hline Musculoskeletal Disorders & 132 & 1.9 & $7.25 \pm 7.37$ & \\
\hline Urinary Tract Diseases & 586 & 8.2 & $6.10 \pm 8.15$ & \\
\hline Signs and Symptoms & 454 & 6.4 & $5.13 \pm 7.57$ & \\
\hline Injuries and Poisoning & 96 & 1.3 & $10.74 \pm 12.03$ & \\
\hline Others & 236 & 3.3 & $3.81 \pm 5.84$ & \\
\hline
\end{tabular}

Results of multivariate analysis (Poisson and negative binomial regression models) are presented in Table 2. Given the data overdispersion, the negative binomial regression model had better fitness than Poisson's model. Akaike information criterion (AIC) value for the Poisson and the negative binomial models was obtained as 77601.163 and 43594.74, respectively.

According to the results of the negative binomial regression model, emergency hospitalization (RR: 0.21), admis- sion to the CCU (RR: 0.33), and male gender (RR: 0.92) were statistically reducing factors of LOS among elderly patients, respectively. Discharge status (deceased, RR: $1.50)$, patients with diagnosis of injuries and poisoning (RR: 1.34), and native residence (RR: 1.10) were factors that statistically increased the length of stay among hospitalized elderly patients. The mean LOS for males was 0.92 times that of females. Also, the mean LOS for open heart surgery $(\mathrm{CABG})$, surgery, heart/cardiac, emergency, and

Table 2. Results of count regression models (Poisson \& Negative binomial regression Models)

\begin{tabular}{|c|c|c|c|c|}
\hline \multirow[t]{2}{*}{ Parameter } & \multicolumn{2}{|c|}{ Poisson Regression } & \multicolumn{2}{|c|}{ Negative binomial regression } \\
\hline & ${ }_{(\mathrm{RR})} e^{\beta}$ & $\mathrm{p}$ & $(\mathrm{RR}) e^{e^{\beta}}$ & $\mathrm{p}$ \\
\hline$y$-intercept & 11.31 & $<0.001$ & 9.89 & $<0.001$ \\
\hline \multicolumn{5}{|l|}{ Gender } \\
\hline Female (reference) & - & & - & \\
\hline Male & 0.91 & $<0.001$ & 0.92 & 0.002 \\
\hline \multicolumn{5}{|l|}{ Type of hospitalization } \\
\hline Elective (reference) & - & & - & \\
\hline Emergency & 1.17 & $<0.001$ & 0.21 & $<0.001$ \\
\hline \multicolumn{5}{|l|}{ Season of hospital visit } \\
\hline Spring (reference) & - & & - & \\
\hline Summer & 0.99 & 0.003 & 1.005 & 0.893 \\
\hline Fall & 0.92 & $<0.001$ & 0.95 & 0.172 \\
\hline Winter & 0.86 & $<0.001$ & 0.92 & 0.022 \\
\hline \multicolumn{5}{|l|}{ Residence } \\
\hline Non-native (reference) & - & & - & \\
\hline Native & 1.08 & $<0.001$ & 1.1 & 0.001 \\
\hline \multicolumn{5}{|l|}{ Discharge status } \\
\hline Recovery (reference) & - & & - & \\
\hline Personal satisfaction & 0.93 & $<0.001$ & 0.93 & $<0.001$ \\
\hline Deceased & 1.5 & $<0.001$ & $\underline{1.5}$ & $<0.001$ \\
\hline Follow up treatment & 0.75 & $<0.001$ & $\overline{0.75}$ & $<0.001$ \\
\hline
\end{tabular}




\begin{tabular}{|c|c|c|c|c|}
\hline \multirow[t]{2}{*}{ Parameter } & \multicolumn{2}{|c|}{ Poisson Regression } & \multicolumn{2}{|c|}{ Negative binomial regression } \\
\hline & $(\mathrm{RR}) e^{e^{\beta}}$ & $\mathrm{p}$ & $(\mathrm{RR}) \boldsymbol{e}^{\beta}$ & $\mathrm{p}$ \\
\hline \multicolumn{5}{|l|}{ Ward/Department } \\
\hline Internal (reference) & - & & - & \\
\hline Surgery & 0.63 & $<0.001$ & 0.63 & $<0.001$ \\
\hline ICU & 1.01 & 0.766 & 1.01 & 0.762 \\
\hline Heart/Cardio & 0.44 & $<0.001$ & 0.44 & $<0.001$ \\
\hline Open Heart Surgery (CABG) & 0.93 & 0.001 & 0.93 & 0.001 \\
\hline $\mathrm{CCU}$ & 0.33 & $<0.001$ & 0.33 & $<0.001$ \\
\hline Emergency & 0.4 & $<0.001$ & 0.4 & $<0.001$ \\
\hline \multicolumn{5}{|l|}{ Diagnosis } \\
\hline Infectious and parasitic disease(reference & - & & - & \\
\hline Cancers & 0.85 & $<0.001$ & 0.83 & 0.022 \\
\hline Metabolic and endocrine disease & 0.8 & $<0.001$ & 0.79 & 0.032 \\
\hline Diseases of the nervous system & 1.07 & 0.025 & 1.06 & 0.592 \\
\hline Circulatory system diseases & 1.08 & $<0.001$ & 1.07 & 0.323 \\
\hline Diseases of the respiratory system & 1.09 & $<0.001$ & 1.03 & 0.735 \\
\hline Gastrointestinal diseases & 0.86 & $<0.001$ & 0.85 & 0.042 \\
\hline Musculoskeletal disorders & 0.88 & 0.001 & 0.83 & 0.122 \\
\hline Urinary Tract Infection & 0.74 & $<0.001$ & 0.68 & $<0.001$ \\
\hline Signs and symptoms & 0.69 & $<0.001$ & 0.66 & $<0.001$ \\
\hline Injuries and poisoning & 1.35 & $<0.001$ & 1.34 & 0.025 \\
\hline Others & 0.51 & $<0.001$ & $\overline{0.51}$ & $<0.001$ \\
\hline
\end{tabular}

CCU patients was $0.93,0.63,0.44,0.40$, and 0.33 times than those who were admitted to the internal ward, respectively (Table 2).

\section{Discussion}

This study included a relatively large number of elderly patients admitted to Ghaem hospital. Findings indicated discharge time is one of the most important factors affecting LOS in elderly patients, with higher LOS in those who were admitted to internal medicine wards and intensive care units. Vejdani et al reported higher LOS for elderly individuals who were admitted to intensive care units (13). Considering that mortality surges with increase in LOS; therefore, we should find a solution to reduce LOS in these wards (14).

In this hospital, the maximum LOS was observed in ICU and internal medicine wards, respectively. The minimum LOS was also observed in the CCU ward. The results of the univariate analysis in this study showed no significant relationship between the type of insurance and LOS, which were inconsistent with the results of Vejdani et al's study $(15,16)$. This contradiction seems to be due to a very small percentage of patients who had no health insurance or used others' insurance, and thus they were excluded from the study. The age variable was significant in the univariate analysis, but when it was included in the regression model, it was not correlated with the LOS, which was inconsistent with the other studies (15-17). The present study also showed a significant relationship between gender and LOS both in univariate and regression models. Although the results of other studies were consistent with those of the present study (18), patients' gender is considered to have no significant effect on LOS. The mean LOS was not significantly different between men and women, and the statistical significance of this variable was due to the large sample size. The results of the binomial regression model showed that the mean LOS in individuals who are admitted to the emergency depart- ment is 1.2 times more than those who are admitted electively. The discharge status variable in this study, similar to Arab et al's study, was one of the important and significant variables (16), and the mean LOS in the deceased patients was higher than other individuals, which can be due to the severity of the patients' health condition. The present study also showed a significant relationship between season variable and LOS in the univariate and in Poisson's regression models, but not in the negative binomial regression.

The maximum and minimum LOS was seen during the spring and winter, respectively. In the present study, the maximum LOS was obtained for patients with respiratory system diseases; however, Ravangard et al showed that patients with endocrine, nutritional and genitourinary diseases stay in hospital for a longer period due to tests and radiography and longer treatment course. This inconsistency may be due to the number of individuals with these diseases, which was low compared to those suffering from other diseases (19). A study by Bhirommuang et al (20) revealed that severely malnourished elderly patients were at higher risk for increased LOS (men: 12.46 days and women: 11.81 days) than patients with normal to mild risk of malnutrition. Moreover, functional capacity was a strong predictor of LOS. Therefore, it can be justified that poor physical performance is associated with loss of skeletal muscle mass and impaired function, which can result from malnutrition and a sedentary lifestyle (21). Furthermore, the decline in functional capacity impacts the quality and quantity of food intake (22). They also reported that the type and amount of dietary intake in the past 2 weeks were robust predictors of LOS. Unfortunately, assessing the effect of this variable in the present study was not possible.

Findings of the present study should be interpreted with caution in the context of limitations of the available data. The role of residual confounding (life style and psychological factors, including living alone or living with other 
relatives and background chronic diseases) should be considered because they could affect the LOS of the elderly. Because modifiable factors, such as nutritional status, history of tobacco smoking, and physical activity, were not fully recorded in hospital information system, they could not be investigated in the present study. However, they seem to be appropriate choices reducing the LOS in hospital.

\section{Conclusion}

In conclusion, length of stay in hospital among the elderly patients is largely the result of multiple factors and the negative binomial regression model is a better statistical method for estimating the influencing factors.

\section{Acknowledgement}

This study was approved by Institutional Review Board of Mashhad University of Medical Sciences (MUMS, Iran). We are also thankful to Clinical Research Development Unit, Ghaem Hospital, Mashhad University of Medical Sciences for their assistance.

\section{Conflict of Interests}

The authors declare that they have no competing interests.

\section{References}

1. United Nations, Department of Economic and Social Affairs, Population Division (2015). World Population Ageing 2015 (ST/ESA/SER.A/390).

2. Mosotti L, Ceccarelli E, Cappelli R, Barabesi L, Guerrini M, Forconi $\mathrm{S}$. Length of hospitalization in elderly patients with community_acquired pneumonia. Aging Clin Exp Res. 2000;12:3541.

3. Lim A, Tongkumchum P. Methods for analyzing hospital length of stay with application to inpatients dying in Southern Thailand. Glob J Health Sci. 2009;1(1):27.

4.Zhang J, Harvey C, Andrew CJA. Factors associated with length of stay and the risk of readmission in an acute psychiatric inpatient facility: a retrospective study. Aust N Z J Psychiatry. 2011;45(7):57885 .

5. Serrani D, Galfetti G, Rodríguez C. Factors associated with length of stay and the risk of readmission in an acute psychiatric inpatient facility: A retrospective study. Vertex. 2017;28(134):260-70.

6. Beak H, Cho M, Kim S, Hwang H, Song M, Yoo S. Analysis of length of hospital stay using electronic health records: a statistical and data mining approach. PLoS One. 2018; 13(4):1-16.

7. Soyiri IN, Reidpath DD, Sarran C. Asthma length of stay in hospitals in London 2001-2006: demographic, diagnostic and temporal factors. PLoS One. 2011;6(11):27184

8. Nikpour S, Habibi Sola A, Seiedoshohadaei M, Haghani H. Health promotion behaviors and quality of life among elderly in West area in Tehran-Iran 2006: a cross-sectional survey. Eur J Sci Res. 2007;18(1):86-95.

9. WHO. Definition of an older or elderly person. 2009 [cited 2010; Available from: http://www.who.int/healthinfo/survey/ageingdefn older/en/index.html.

10. Kiani S, Bayanzadeh M, Tavalaei M, Hogg RS. The Iranian Population is Graying: Are we ready? Arch Iran Med. 2010;13(4):333-339.

11. United Nation. World Population Ageing: 1950-2050, Countries of area: Iran (Islamic Republic of). Available from: http://www.un.org/esa/population/publications/ world ageing 19502050/pdf/113iran.

12. Lim A, Tongkumchum P. Methods for Analyzing Hospital Length of Stay with Application to Inpatients Dying in Southern Thailand. Glob J Health Sci. 2009;1(1):27-32.
13. Vejdani M, Saleh AR, Saffari SE, Borabadi M, Nejatzadeh EZ, Foji S. Assesment the factors affecting on lenth of hospitalization stay for elderly of Vasei hospital in Sabzevar (2014) using count regresion models. J Sabzevar Univ Med Sci. 2016;22(6):1105-1116.

14. Zand S, Rafiei M. Causes and duration of hospitalization and mortality rate in intensive care units in Central province. Iran J Critic Care Nurs. 2010;3(2):63-67.

15. Vahidi R, Koushavar H, Khodayari R. Factors affecting coronary artery patients hospital length of stay of Tabriza Madani hospital; 2005-2006. J Health Adminst. 2006;9(25):63-68.

16. Arab M, Zarei A, Rahimi A, Rezaiean F, Akbari F. Analysis of factors affecting length of stay in public hospitals in Lorestan Province, Iran. Hakim Res J. 2010;12(4):27-32.

17. Coid J, Crome P. Bed blocking in Bromley. BMJ. 1986;292(6530):1253-6.

18. Baharlooei O, Alavi M, Adelmehraban M. Psychosocial factors predicting length of hospitalization in elderly individuals with diabetes in selected hospitals of Isfahan University of Medical Sciences, Isfahan, Iran, in 2015. ARYA Atheroscleros. 2017;13(3):103.

19. Ravangard R, Arab M, Rashidian A, Akbarisari A, Zare A, Salesi M, et al. Hospitalized patients' length of stay and its associated factors in Tehran University of Medical Sciences Women's Hospital using the survival analysis method. J Sch Public Health Inst Public Health Res 2010;8(3).

20. Bhirommuang N, Komindr S, Jayanama K. Impact of nutritional status on length of stay and hospital costs among patients admitted to a tertiary care hospital in Thailand. Asia Pac J Clin Nutr. 2019;28(2):252-259.

21. Santilli V, Bernetti A, Mangone M, Paoloni M. Clinical definition of sarcopenia. Clin Cases Miner Bone Metab. 2014; 11:177-80.

22. Oliveira MR, Fogaça KC, Leandro-Merhi VA. Nutritional status and functional capacity of hospitalized elderly. Nutr J. 2009; 8:54:11-19. 